\title{
Endangered African Wild Dogs (Lycaon pictus Temm.) in Angola: Filling a 50-year gap of knowledge with findings from two National Parks.
}

\author{
Authors: \\ Jacob McC. Overton ${ }^{[1]}$ \\ David Elizalde Castells ${ }^{[2,4]}$ \\ Sara Raquel Figueira Fernandes Elizalde ${ }^{[2,4]}$ \\ Hilária Mita Valério[3] \\ Marta Nsamba Alexandre Zumbo ${ }^{[3]}$ \\ Rosemary Joy Groom ${ }^{[2,4]}$ \\ Sarah M Durant ${ }^{[2,4]}$
}

\section{Affiliations:}

[1] Panthera, 8 West 40th St, 18th Floor, New York, NY 10018, USA

[2] The Range Wide Conservation Program for Cheetah and African Wild Dogs

[3] Instituto Nacional da Biodiversidade e Áreas de Conservação - Ministério do Ambiente - Angola

[4] Institute of Zoology, Zoological Society of London, Regents Park, London NW1 4RY

\section{$1.1 \quad$ Introduction}

The African wild dog (wild dog) Lycaon pictus is classified as endangered by the IUCN (IUCN, 2019). As a wide-ranging species it has a broad distribution, but occurs at very low densities, rarely exceeding more than 2 individuals per $100 \mathrm{~km}^{2}$ (IUCN/SSC, 2012; IUCN/SSC, 2015). Across most of the 19 countries in which wild dogs still occur, populations are in decline (Kuiper et al, 2018), and only an estimated 6,600 individuals remain in the wild (Woodroffe \& Sillero-Zubiri, 2012). The main drivers of decline are habitat change and fragmentation, conflict with livestock and game keepers, infectious disease and loss of prey; and most remaining range is outside protected areas where the species faces heightened exposure to these anthropogenic pressures (Woodroffe et al, 2004; IUCN/SSC, 2012; IUCN/SSC, 2015).

In this context, surveys of promising areas that lack recent information on wild dog status have the potential to identify hitherto unknown populations, and provide valuable information for wild dog conservation. Historically, wild dogs were widespread across Angola, Africa's seventh largest country (IUCN/SSC, 2015), with the first documented wild dog record in 1886, close to what is currently Mupa National Park, and multiple records following from across the country (e.g. Bocage, 1898; CrawfordCabral \& Simões, 1989). However, field research ceased in Angola during the last quarter of the $20^{\text {th }}$ century due to a prolonged period of armed conflict, political unrest and widespread minefields. Thus today, wild dog status in Angola is virtually unknown, with the most recent published evidence over 40 years old (Crawford-Cabral \& Simões, 1989; Huntley, 1971). The cessation of conflict and recent mine removals provide a new opportunity to survey some of Angola's remaining wilderness areas. 
Bicuar and Mupa National Parks (NPs), two large protected areas located in southwest Angola, have suffered extensive human encroachment and settlement during the civil war years and post-war period, which has significantly impacted habitats and wildlife (Ron, 2015; Hines, 2018). This leads to an assumption that wild dogs had likely disappeared alongside the diminished populations of large herbivores, their natural prey. Here we report on a survey to assess the status of wild dogs in Bicuar and Mupa NPs, using a methodology and study design focused on maximizing detection of this species.

\section{$1.2 \quad$ Methods}

The study area encompasses Bicuar and Mupa NPs in southwest Angola and the area between them (Figure 1). The parks fall into three ecoregions: Angolan Miombo Woodlands, Zambezian Baikiaea Woodlands and Angolan Mopane Woodlands (Olson et al, 2001). Bicuar and Mupa were gazetted in 1964 and encompass areas of $6754 \mathrm{~km}^{2}$ and $6600 \mathrm{~km}^{2}$ respectively, with Mupa NP lying $25 \mathrm{~km}$ east of Bicuar NP at the closest point (Elizalde \& Elizalde, 2018).

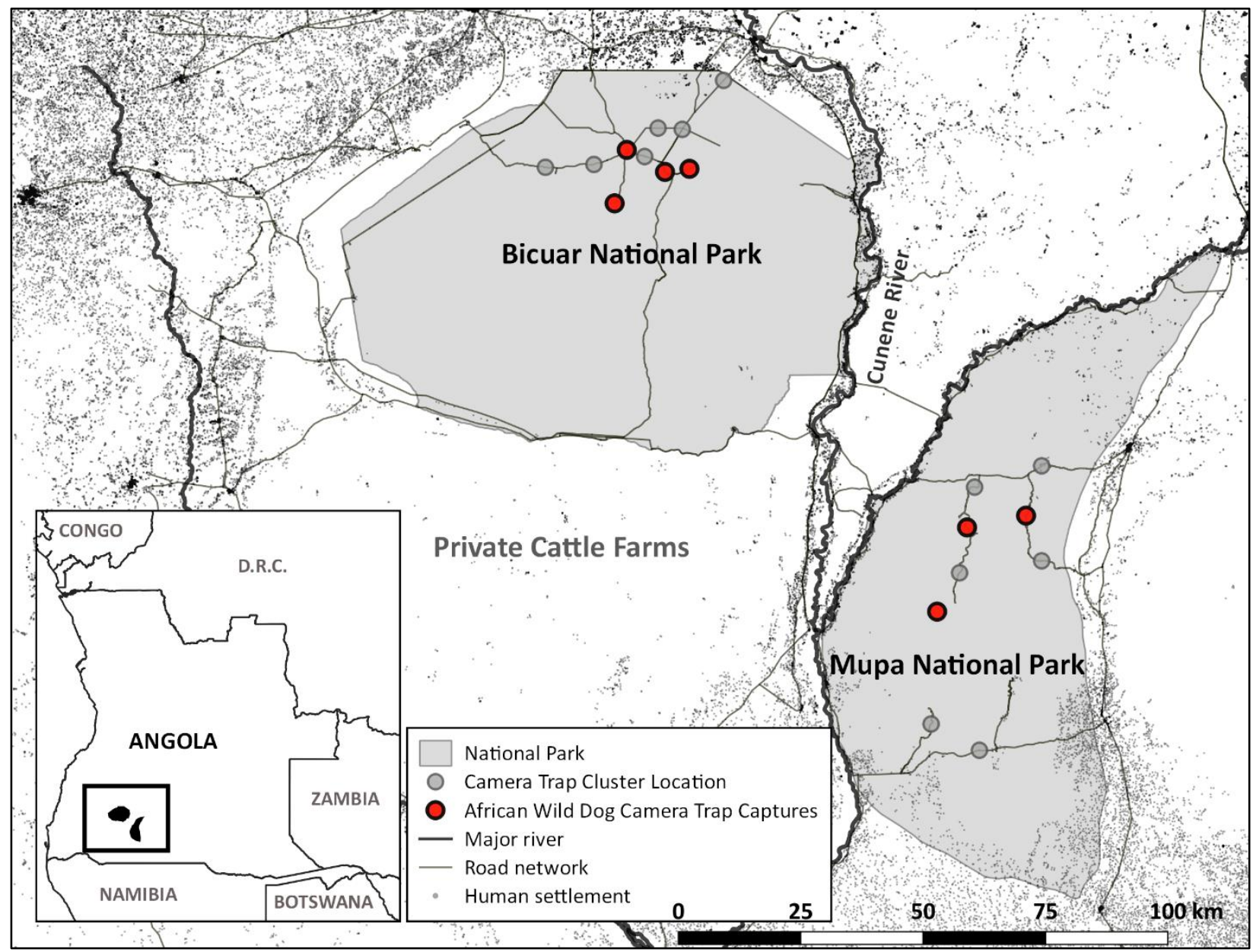

FIGURE 1 - Locations with one or more camera traps and presence of wild dogs. Inset shows location of the study area. (Human settlements data: RAISON, unpublished data) 
Wild dog surveys

Two camera trap surveys were conducted in August to September 2016 as part of a wider large mammal survey, with the specific objective of ascertaining presence and status of wild dog. Cameras traps were deployed around sites that were thought to have the greatest chance of detecting wild dogs, based upon habitat and recent sighting reports. In Bicuar NP, 39 camera traps were deployed over 28 days on average (range 2-33) with the highest survey effort in the core area, where permanent water and greater protection supports the highest abundance of suitable prey species. In Mupa NP, 29 cameras were deployed for 21 days on average (range 10-26), again concentrated in the relatively intact core area, where permanent water was available. Any image of wild dogs taken at the same camera station within a 30-minute period was considered part of the same pack and the set of images used as a single observation event. Wild dogs were individually identified according to their distinctive markings, however, because right and left sides of the dogs could not be matched, the maximum obtained from right or left-side matching was used as the number of individuals detected in each observation event.

Species distribution analysis

Occupancy analysis was used to identify covariates associated with detection of wild dogs at camera trap stations. Camera trap data were divided into seven-day time intervals that were treated as replications (range 1-5 replications). If the last camera trap period was less than seven days, then it was discarded from analyses.

We tested for the effects of five site-based covariate measures of human impacts: 1) whether the camera site was in Bicuar NP or Mupa NP; 2) distance to the centroid of the respective park; 3) minimum distance to respective park boundary; 4) number of households within a $10 \mathrm{~km}$ radius; and 5) distance to nearest household. Centroid locations and distance estimates were obtained using QGIS software (QGIS Development Team 2013). We also tested for the effects of four site and replication covariates based on information obtained from camera traps within each camera trap period and within the same 30 minute interval: number of 1) domestic animals (total number of cattle, goats, sheep, donkeys, dogs, pigs and others), 2) people, 3) vehicles and 4) fire events photographed.

All occupancy analyses were conducted in R using the package unmarked (Fiske \& Chandler 2011). Because of the low number of wild dog detections, models were run with only one covariate at a time and a covariate-based model was selected over the null model if the difference in Akaike Information Criterion (AIC) was greater than two (Burnham \& Anderson, 2003).

\section{$1.3 \quad$ Results}

\section{Wild dog status}

The Bicuar NP survey effort totalled 1123 camera trap days. During the survey, 20 images of wild dogs were obtained from 12 different observation events at 7 camera stations (Table 1), which demonstrated a 
minimum of 6 individual wild dogs living in the core area of Bicuar NP. Larger packs of 7 to 20 individuals were reported by Bicuar NP staff and from adjacent game farms south and east of Bicuar NP, but were not seen during this survey. These preliminary results suggest that there is likely to be a small resident population of wild dogs within Bicuar NP and its environs.

Table 1 Sampling effort and camera trap captures in Bicuar and Mupa National Parks, Angola. RAl is the relative abundance index, calculated as the total number of observation events for all camera traps over all days multiplied by 100 and divided by the total number of camera trap days.

\begin{tabular}{|c|c|c|c|c|c|c|c|c|c|}
\hline \multirow[t]{2}{*}{ Site } & \multirow{2}{*}{$\begin{array}{l}\text { Average } \\
\text { sampling } \\
\text { period } \\
\text { (days) }\end{array}$} & \multirow{2}{*}{$\begin{array}{l}\text { Number of } \\
\text { camera } \\
\text { stations }\end{array}$} & \multirow{2}{*}{$\begin{array}{l}\text { Number of } \\
\text { camera trap } \\
\text { days }(24 \mathrm{~h})\end{array}$} & \multirow{2}{*}{$\begin{array}{l}\text { Number of } \\
\text { photos of } \\
\text { wild dogs }\end{array}$} & \multirow{2}{*}{$\begin{array}{l}\text { Number of sites } \\
\text { where wild dogs } \\
\text { were captured }\end{array}$} & \multirow{2}{*}{$\begin{array}{l}\text { Number of wild } \\
\text { dog observation } \\
\text { events }\end{array}$} & \multirow[t]{2}{*}{ RAI } & \multicolumn{2}{|c|}{ Number of individuals } \\
\hline & & & & & & & & $\begin{array}{l}\text { Left } \\
\text { hand } \\
\text { side }\end{array}$ & $\begin{array}{l}\text { Right hand } \\
\text { side }\end{array}$ \\
\hline Bicuar NP & 28 & 39 & 1122 & 20 & 7 & 12 & 1.07 & 5 & 6 \\
\hline Mupa NP & 21 & 29 & 584 & 11 & 4 & 4 & 0.68 & 7 & 4 \\
\hline
\end{tabular}

The Mupa NP survey effort totalled 584 camera trap days, and obtained 11 images of wild dogs from four observation events at four camera stations, providing a minimum population estimate of 7 individuals (Table 1). The relative abundance index (RAI) was higher at Bicuar NP (1.07) than at Mupa NP (0.68). Local officials and communities reported observing wild dogs in small numbers in the central uninhabited regions of Mupa NP, and along the eastern boundary, but provided no observations of larger packs. There were no reports of wild dogs in the unprotected area between Bicuar and Mupa NPs on the eastern side of Cunene River, which may indicate a lack of movement between the two parks. These results suggest that wild dogs in Mupa NP most likely occur in small groups, numbering less than five individuals, which could be same-sex dispersal groups or resident packs.

Table 2. Mean (and standard error) of measures of anthropogenic variables observed at camera trap stations used as covariates in analyses.

\begin{tabular}{lll}
\hline & Bicuar NP & Mupa NP \\
& Mean (+/- SE) & Mean (+/- SE) \\
\hline Distance to nearest household $(\mathrm{km})$ & $13.09(6,96)$ & $8.48(4.33)$ \\
Distance to NP centroid $(\mathrm{km})$ & $26.20(9.09)$ & $21.70(6.72)$ \\
Closest distance to NP border $(\mathrm{km})$ & $15.79(7.30)$ & $16.12(5.20)$ \\
Number of households within 10km & $165.31(423)$ & $22.11(42)$ \\
Mean number of domestic animals captured per camera trap day & $0.001(0.005)$ & $0.94(2.29)$ \\
Mean number of people captured per camera trap day & $0.158(0.178)$ & $0.243(0.487)$ \\
Mean number of vehicles captured per camera trap day & $0.435(0.704)$ & $0.086(0.190)$ \\
Mean number of fire events per camera trap day & $0.080(0.117)$ & $0.022(0.043)$ \\
\hline
\end{tabular}


Anthropogenic activity

Camera traps were placed at sites in the two parks where wild dogs were most likely to be detected. While these areas were often in the more remote areas of each park, they were still subject to substantial anthropogenic activity. The average number of households within $10 \mathrm{~km}$ of camera trap stations was skewed upwards in Bicuar NP due to a large settlement with $10 \mathrm{~km}$ of some of the camera traps. In fact, only 33\% of cameras in Bicuar NP, compared with $72 \%$ in Mupa NP, had households within $10 \mathrm{~km}$ and therefore substantially more domestic animals and people were observed at camera trap stations in Mupa NP than Bicuar NP (Table 2). More vehicles were detected in Bicuar NP than Mupa NP, and, although fire events were detected at both locations, they were substantially more widespread in Bicuar NP (74\% of camera stations) than in Mupa NP (31\% of camera stations).

\section{Occupancy analysis}

Occupancy analysis showed that the best predictor of wild dog occupancy at camera trap sites was the distance to the centroid of the national park, such that the further a camera station was from the centroid, the less likely it was to be occupied by wild dogs (Table 3).

Table 3. Covariate analysis of wild dog occupancy at camera trap stations. Models are listed according to increasing AIC. The top model was the only model where the AIC showed an improvement in model fit ( $\triangle A I C>2)$ compared with the null model. Coefficients are reported only for those models where $p<0.1$. *indicates sitebased covariate tindicates sample-period $x$ site-based covariates

\begin{tabular}{lllll}
\hline Model & Coefficient (+/-SE) & $\mathrm{p}$ & AIC & $\Delta$ AIC \\
\hline Distance to NP centroid $(\mathrm{km})^{*}$ & $-0.150(0.066)$ & 0.022 & 101.39 & 0.00 \\
Closest distance to NP border $(\mathrm{km})^{*}$ & $0.124(0.071)$ & 0.080 & 105.37 & 3.99 \\
Number of fire events detected ${ }^{*}$ & $1.982(1.108)$ & 0.074 & 105.40 & 4.01 \\
Distance to nearest household $(\mathrm{km})^{*}$ & & 0.106 & 106.42 & 5.04 \\
Number of people detected $\dagger$ & & 0.142 & 106.83 & 5.44 \\
Number of households within 10km* & & 0.554 & 107.07 & 5.69 \\
Null model & & & 107.31 & 5.92 \\
Park (Bicuar or Mupa)* & & 0.468 & 108.77 & 7.38 \\
Number of domestic animals detected $\dagger$ & & 0.761 & 109.21 & 7.83 \\
Number of vehicles detected $\dagger$ & & 0.599 & 109.35 & 7.96 \\
\hline
\end{tabular}

\section{Discussion}

Here we have provided, to the best of our knowledge, the first peer-reviewed published records of African wild dogs In Angola in almost 50 years. Our results demonstrate the survival of wild dog populations in Bicuar NP and Mupa NP in southwest Angola, across an area that represents $9.5 \%$ of the 
known global distributional range of wild dogs in Angola (see Funston et al 2017, Groom et al 2018, Elizalde et al 2019). This ranks Angola fifth in Africa in terms of total area of wild dog resident range, making the country one of the most important for the conservation of this species.

Our results suggest that the wild dog population in Bicuar NP is likely to be in better shape, with higher reported pack sizes, than the population in Mupa NP. Our analyses also indicated that wild dogs were more likely to occupy areas towards the centre of the protected areas and away from park borders where human encroachment was extensive. Worryingly, the small pack sizes observed in Mupa NP indicates that the wild dog population there may be transitory, possibly due to insufficient permanent water, law enforcement and/or management.

Our camera trap survey was biased towards those areas with the highest likelihood of detecting wild dogs, thus our data were inappropriate for a comprehensive analysis of wild dog occupancy across the landscape. In some situations, because of the need to optimise detection of presence of wild dogs, camera traps were close together, and hence there may be a degree of spatial autocorrelation between camera traps. Moreover, the low number of detections of wild dogs meant that we were only able to include a single covariate at a time within our analysis, in order to ensure model convergence. Thus, our analysis of occupancy covariates is extremely preliminary. However, the higher detections within the core areas of the NPs provides preliminary evidence that wild dog persistence in this landscape is likely to depend on large tracts of habitat protected from human encroachment.

The high levels of encroachment and human activity observed within both parks, as well as rapid habitat change and infrastructure development in the surrounding areas raise concerns for the long-term viability of these wild dog populations. Other potential threats such as infectious diseases transmitted from domestic dogs (Woodroffe et al, 2012), are likely to be present as the human population in and around the NPs supports a large population of unvaccinated domestic dogs. The two parks are separated by only $25 \mathrm{~km}$ at their closest points, however two major rivers, the Cunene and Calonga, both heavily settled, flow between the parks and are likely to create a significant barrier to wild dog movement. Without restoring this connectivity, the wilderness areas of Mupa NP and core protected area of Bicuar NP are likely to be too small to support wild dog populations that are viable in the long term.

Our study represents the first post-war publication on wild dogs in Angola, and provides important information on the species distribution and threats. These results have already catalysed action by the Angolan Ministry of Environment to recover and restore Mupa NP and to develop the first management plan for Bicuar NP. Data is also being used to inform implementation of Angola's National Action Plan for the Conservation of Cheetah and African Wild Dog (INBAC, 2016). We now need an urgent assessment of population status and trends of the wild dog populations in Bicuar and Mupa NPs, including establishing the extent of surrounding area used by the species. It would be useful to conduct another more comprehensive survey for a longer period, or perhaps during the known wild dog denning season to ascertain whether observed packs and groups o wild dogs are resident or transitory in the respective parks. Of particular urgency is the need to identify and restore corridors between the two NPs in order to better safeguard the long-term viability of the population. 


\section{$1.4 \quad$ Acknowledgements}

We thank the Angolan Ministry of Environment for permission to conduct this research. Funding was provided through a generous donation from Paul Maritz. We would also like to thank J. Kandungo, G. Alexandre, the Bicuar NP scouts and staff, the headmen and people of Mupa NP and surrounds, the volunteers at CATalogue for identifying camera trap photos, Ross Pittman for help with CATalogue and analysis of resulting data, Kim Young-Overton and Carolyn Whitesell. The RWCP thanks the Howard G Buffett Foundation for core funding support.

\section{$1.5 \quad$ Data Statement}

The data that support the findings of this study are available from the corresponding author upon reasonable request.

\subsection{References}

Bocage JVB (1898) Nota sobre a presença do Lycaon pictus Temm. no sertão de Benguela. Jornal de Sciencias Mathematicas.

Burnham, K. P. and D. R. Anderson. 2003. Model Selection and Multimodel Inference: A Practical Information-Theoretic Approach. Springer New York.

Crawford-Cabral J, Simões AP (1989) Distributional data and notes on Angolan carnivores (Mammalia: Carnivora) II - Larger species. Garcia de Orta, Série de Zoologia, 15(2): 9-20.

David M. Olson, Eric Dinerstein, Eric D. Wikramanayake, Neil D. Burgess, George V. N. Powell, Emma C. Underwood, Jennifer A. D'amico, Illanga Itoua, Holly E. Strand, John C. Morrison, Colby J. Loucks, Thomas F. Allnutt, Taylor H. Ricketts, Yumiko Kura, John F. Lamoreux, Wesley W. Wettengel, Prashant Hedao, Kenneth R. Kassem, Terrestrial Ecoregions of the World: A New Map of Life on Earth: A new global map of terrestrial ecoregions provides an innovative tool for conserving biodiversity, BioScience, Volume 51, Issue 11, November 2001, Pages 933-938,

Davies HT, du Toit JT (2004) Anthropogenic factors affecting wild dog Lycaon pictus reintroductions: a case study in Zimbabwe. Oryx, 38(1): 32-39.

Elizalde SRF, Elizalde DC (2018) Institutional Revision. In: Bicuar Management Plan Product 1 Chapter 1. Unpublished report. INBAC-RWCP

Elizalde SRF, Elizalde DC, Lutondo EK, Groom RJ, Kesch K, Durant S (2019) Luando Natural Integral Reserve, Angola. A large and medium sized mammal survey. Unpublished report. Instituto Nacional de 
Biodiversidade e Áreas de Conservação (INBAC) and The Range Wide Conservation Programme for Cheetah and African Wild Dog (RWCP).

Fennessy, J., Bidon, T., Reuss, F., Kumar, V., Elkan, P., Nilsson, Maria A., Vamberger, M., Fritz, U. and Janke, A. (2016) 'Multi-locus Analyses Reveal Four Giraffe Species Instead of One', Current Biology, 26(18): 2543-2549.

Fiske, I. and Chandler, R. B. (2011). unmarked: An R package for fitting hierarchical models of wildlife occurrence and abundance. Journal of Statistical Software 43:1-23.

Funston PJ, Frank L, Stephens T, Davidson Z, Loveridge A, Macdonald DM, Durant S, Packer C, Mosser A, Ferreira SM (2010) Substrate and species constraints on the use of track incidences to estimate African large carnivore abundance. Journal of Zoology, London 281: 56-65.

Funston P, Henschel P, Petracca L, Maclennan S, Whitesell C, Fabiano E, Castro I (2017) The distribution and status of lions and other large carnivores in Luengue-Luiana and Mavinga National Parks, Angola. KAZA TFCA Secretariat (KAZA).

Groom R, Elizalde D, Elizalde S, Sá S, Alexandre G (2018) Quiçama National Park, Angola. A large and medium sized mammals survey. Unpublished report. INBAC-RWCP.

Hines CJH (2018) Vegetation of Bicuar National Park: a rapid survey (28/03 - 05/04/2018). In: Bicuar Management Plan Product 1 - Chapter 3. Unpublished report. INBAC-RWCP.

Huntley BJ (1971) Guia Preliminar dos Parques e Reservas de Angola. Direcção Provincial dos Serviços de Veterinária, no 3, Luanda, Angola

INBAC - National Institute for Biodiversity and Conservation Areas (2016) National Conservation Action Plan for Cheetah and African Wild Dogs in Angola. Angolan Ministry of Environment. Luanda.

IUCN/SSC (2007) Regional Conservation Strategy for the Cheetah and African Wild Dog in Eastern Africa, Gland, Switzerland.

IUCN/SSC (2012) Regional Conservation Strategy for the Cheetah and African Wild Dog in Western, Central and Northern Africa, Gland, Switzerland.

IUCN/SSC (2015) Review of the Regional Conservation Strategy for the Cheetah and African Wild Dog in Southern Africa, IUCN/SSC, Gland, Switzerland and Range Wide Conservation Program for Cheetah and African Wild Dogs,

IUCN (2019) The IUCN red list of threatened species. Version 2019-1. https://newredlist.iucnredlist.org (accessed 12 April 2019). 
Kuiper T, Dickman AJ, Hinks AE, Sillero-Zubiri C, Macdonald EA, Macdonald DW (2018) Combining biological and socio-political criteria to set spatial conservation priorities for the endangered African wild dog. Animal Conservation, 21, pp. 376-386.

LeFlore EG, Fuller TK, Tomeletso M, Stein AB (2019) Livestock depredation by large carnivores in northern Botswana. Global Ecology and Conservation. doi.org/10.1016/j.gecco.2019.e00592

MINAMB - Ministério do Ambiente de Angola (2016) Parque Nacional da Mupa. https://www.biodiversidade-angola.com/area/parque-nacional-da-mupa/ (accessed 15 April 2019)

Oksanen J, Blanchet FG, Friendly M, Kindt R, Legendre P, McGlinn D, Minchin PR, O'Hara RB, Simpson GL, Solymos P, Stevens MHH, Szoecs E, Wagner H.(2019). vegan: Community Ecology Package. R package vers ion 2.5-4. https://CRAN.R-project.org/package=vegan

QGIS Development Team. 2013. QGIS Geographic Information System. Open Source Geospatial Foundation Project. http://qgis.osgeo.org

Ron T (2015) Preliminary Assessment of eight National Parks and one Strict Nature Reserve for planning further Project and Government Interventions. Ministério do Ambiente - Projecto Nacional da Biodiversidade: Conservação do Parque Nacional do lona.

White $F$ (1983) The Vegetation of Africa; a descriptive memoir to accompany the UNESCO/AETFAT/UNSO vegetation map of Africa. UNESCO. Switzerland. 356pp.

Winterbach CW, Ferreira SM, Funston PJ, Somers MJ (2016) Simplified large African carnivore density estimators from track indices. PeerJ: e2662. doi: 10.7717/peerj.2662.

Woodroffe R, McNutt JW, Mills MJL (2004) African wild dog Lycaon pictus (Temminck, 1820). In: C. SilleroZubiri, M. Hoffman, D.W. Macdonald (Eds.), Canids: Foxes, Wolves, Jackals and Dogs Status Survey and Conservation Action, IUCN/SSC Canid Specialist Group, Gland, Switzerland, and Cambridge, UK (2004), pp. 174-183.

Woodroffe R, Prager KC, Munson L, Conrad PA, Dubovi EJ, et al. (2012) Contact with Domestic Dogs Increases Pathogen Exposure in Endangered African Wild Dogs (Lycaon pictus). PLoS ONE 7(1): e30099. doi:10.1371/journal.pone.0030099.

Woodroffe, R. and J. R. Ginsberg. 1998. Edge effects and the extinction of populations inside protected areas. Science 280:2126-2128.

Woodroffe R \& Sillero-Zubiri C (2012) Lycaon pictus. The IUCN Red List of Threatened Species 2012: e.T12436A16711116. 